\title{
Recurrent Perineal Hernia After Benign Pelvic Reconstructive Surgery
}

\author{
Yasser Rodriguez, MD, MBA, ${ }^{1,2}$ Brittany Casey, BS, ${ }^{2}$ Richard E. Bazan, MD, MBA, ${ }^{2}$ Rita Zeidan, BS, \\ Joanna Tsikis, BS, ${ }^{2}$ and Isidro A. Cardella, MD, FACOG ${ }^{3}$
}

\begin{abstract}
Background: Secondary acquired perineal hernias are rare events usually associated with extensive pelvic surgery. Although most are asymptomatic, when symptoms are present surgical intervention is warranted. There is currently no consensus regarding the management of these hernias. An unusual case of a recurrent perineal hernia following sacrospinous fixation resulting in large bowel incarceration is reported. Case: A 64-year-old woman presented with an anterior vaginal wall prolapse and multiple pelvic-floor defects. She subsequently underwent a sacrospinous fixation and enterocele repair. The enterocele recurred and she underwent a second enterocele repair. Approximately 6 months later, she presented with a perineal hernia that involved an incarceration of the large bowel. Results: The hernia was reduced, the pelvic-floor defect was repaired, and a biologic, absorbable mesh was applied. Approximately 5 months later, the patient presented with a recurrence of the perineal hernia. The hernia was reduced and this time a synthetic, nonabsorbable mesh was used, and there were no signs of recurrence at 6 months' follow-up. Conclusions: Acquired perineal hernias are extremely rare events, especially when they recur and involve large bowel incarceration. Several factors may influence the development and possible recurrence of secondary acquired perineal hernias, including lifestyle, occupation, gestational history, and past medical and surgical history. The use of a nonabsorbable mesh to prevent recurrence is suggested, although current literature reports success rates that are fairly similar for users of both absorbable and nonabsorbable meshes. (J GYNECOL SURG 28:230)
\end{abstract}

\section{Introduction}

A N ACQUIRED PERINEAL HERNIA IS A RARE EVENT. It is even rarer when it recurs within the same patient and involves large bowel incarceration. In 2008, Salameh reported that $<100$ cases had been cited in the literature, a figure that has remained largely unchanged since the early 1990s. ${ }^{1}$ Acquired pelvic diaphragm hernias can be classified as either primary, occurring in patients who have had no previous surgery, or secondary; these are seen in patients who have had pelvic surgery and in which the hernia is postincisional. ${ }^{2}$ Primary hernias are often diagnosed in patients who have had increased intra-abdominal pressure in adulthood, as occurs during multiple gestations. ${ }^{2}$ When secondary acquired perineal hernias occur, they are more often associated with radical pelvic surgery, such as pelvic exenteration, abdominoperineal resection of the anorectum, and radical cystourethectomy, among other procedures. ${ }^{2}$ Incidence rates have been reported to be between $0.6 \%$ after abdominoperineal resection of the anorectum, to up to $3 \%$ after pelvic exenteration. ${ }^{2}$ The rate of occurrence correlates with the magnitude of the operation. ${ }^{3}$ Secondary acquired perineal hernias are less commonly associated with relatively less-invasive procedures, such as sacrospinous ligament suspension and pelvic-floor reconstruction. A worthwhile point to mention is that a perineal hernia is not the same as a perineocele, which is a defect through the muscular wall on the right side. In contrast, a sigmoidocele is a defect on the left side, the side of the sigmoid colon. These conditions have also been reported in the literature but are not related to the case discussed here. An exceptionally rare case of a recurrent perineal hernia involving large bowel incarceration in a 64-year-old woman, originally undergoing sacrospinous ligament fixation and pelvic floor reconstruction, is presented.

\section{Case}

A gravida 3, para 3 64-year-old white woman presented to the University of Miami Health System/Jackson Memorial Hospital in February 2009 because of urinary incontinence.

\footnotetext{
${ }^{1}$ University of Michigan Health Systems, Ann Arbor, Michigan.

${ }^{2}$ University of Miami Miller School of Medicine, Miami, Florida.

${ }^{3}$ Miami, Florida.
} 
(From this point, dates in this article are referenced in number of months from this initial presentation.) The patient had a past medical history significant for hypertension, diabetes, obesity, and dyslipidemia; her past surgical history was significant for a laparoscopic cholecystectomy. She reported a 1 year history of stress urinary incontinence. Physical examination revealed an anterior vaginal wall prolapse in addition to multiple pelvic floor defects. This particular patient's Pelvic Organ Prolapse Quantitation system (POPQ) score was a 4 according to standard measurements described in Ostergard's Urogynecology and Pelvic Floor Dysfunction. ${ }^{4}$ Her initial workup included urodynamic testing, a pelvic and transvaginal ultrasound, and a cystourethroscopy. Urodynamic testing revealed a stable bladder and a normal bladder capacity. The ultrasound demonstrated the presence of an 8.3-cm cystocele and no masses or cystic lesions within the pelvic floor. The cystourethroscopy revealed a normal distal, mid and proximal urethra with no evidence of diverticula. There was no evidence of any urethral abnormalities. Upon evaluation of the bladder, the dome, side-walls, and posterior wall all appeared normal. The reason that cystoscopy and ultrasound were performed on this patient was that she had complained on initial presentation of subjective stress urinary incontinence for the past year. This was the presenting symptom for which she was seeking medical attention. The urodynamics study confirmed objectively that she did indeed have urinary stress incontinence. Based on the surgeon's collective experience over the past 22 years, cystoscopy was considered the standard of care for cases such as these, in which better visualization of the urethra is needed to assess its degree of mobility.

At this time, the patient underwent bilateral sacrospinous fixation with a sling, bilateral paravaginal defect repair, a Kelly-Kennedy plication and implantation of a porcine dermal graft (Pelvicol ${ }^{\circledR}$ ), enterocele repair, a Bullard-Watson reconstruction of the perineal body, and implantation of a graft (Pelvicol). The Kelly-Kennedy plication was performed in conjunction with a sling and not a graft because it was not used for the incontinence, but rather to repair the central defect of the translocated perineal body. The Bullard-Watson reconstruction is a technique named after two early urogynecologists at the University of Miami, pioneered by Dr. Henry Landsman, MD, at the University. It is used primarily at the University of Miami/Jackson Memorial Hospital with a few exceptions. This technique refers to a specific plication of the levator muscles, which gives depth to and helps to rebuild the perineal body. Initially, the operation was successful.

\section{Results}

The patient reported a significant reduction of both her symptoms and improvement in her quality of life at followup. Unfortunately, the patient's occupation, food service inventory at a local school, involved constant heavy lifting, which resulted in an increase in intra-abdominal pressure. She presented to the University of Miami Hospital at 13 months with an exacerbation of her incontinence and discomfort. After a similar workup consisting of a thorough examination and an ultrasound, it was determined that she had a recurrent enterocele in addition to evidence of a physical displacement of the perineal body. The following

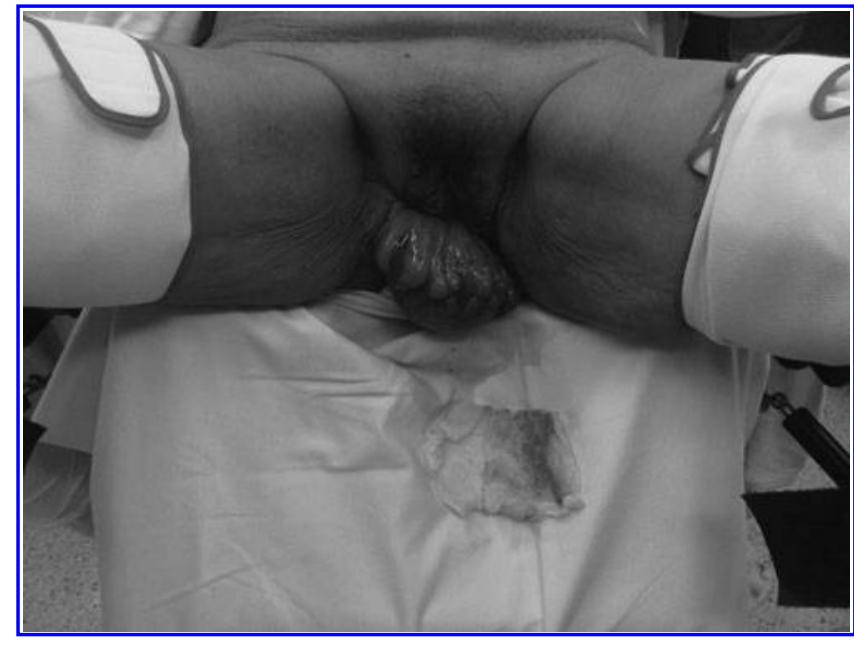

FIG 1. The patient is in the lithotomy position. Excision of the hernia sac reveals the presence of large bowel.

month, the patient underwent a surgical revision of the enterocele, which involved a bilateral sacrospinous repair with the placement of a graft. She reported a reduction of her symptoms and was found to be stable at both the 1 and 2 month follow-up.

At 20 months, $\sim 6$ months after her pelvic procedure, the patient reported to the University of Miami Hospital on an emergency basis complaining of severe pain. Initial examination revealed a large herniated mass protruding through the right perineal, paralabial region. Emergent surgical intervention was performed. It was determined that the patient had incarceration of her large bowel through this herniation (Figs. 1 and 2). Her vagina and rectum were intact. As part of the emergent intervention, a flexible sigmoidoscopy was performed in order to determine the viability of the colon; the colon appeared grossly normal, pink, and viable. Using saline, there was no evidence of leaks. In addition, the descending sigmoid and rectum were intact and no abnormalities were noted. Two surgical procedures were performed simultaneously with the patient in the

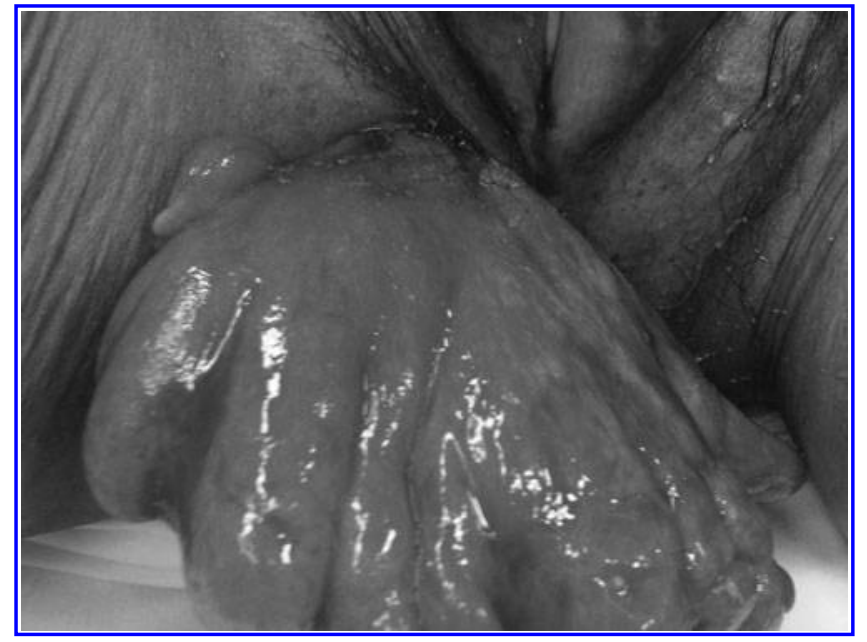

FIG. 2. The patient is in the lithotomy position. Large bowel is seen protruding through a defect in the the right perineal, paralabial region. 
lithotomy position: (1) a surgical reduction of the incarcerated mass with repair of the three layers and (2) laparoscopic placement of a porcine dermal collagen mesh (Permacol, Tissue Science Laboratories plc, Covington, GA). The patient tolerated the procedures well, and all was normal at 1 and 2 month follow-up. Unfortunately, the patient presented to the University of Miami Hospital at 25 months with a large, protruding mass in the identical location as her previous hernia. The team felt an intervention was warranted in order to prevent progression of the herniation and any possible incarceration of bowel. An identical procedure was performed with the exception that a synthetic, nonabsorbable mesh was used (Gynemesh $\left.{ }^{\circledR}\right)$. The patient appeared to be well at her 6-month postoperative follow-up appointment with no signs of recurrence (31 months after her initial presentation).

\section{Discussion}

Acquired secondary perineal hernias are an infrequent complication usually associated with major pelvic surgery. When postoperative perineal hernias do occur, the majority of them are usually asymptomatic. ${ }^{5}$ Traditionally, the prevalence rate for symptomatic secondary perineal hernias is $0.62 \%$ (21 out of 3,387 cases). ${ }^{5}$ The most common symptom associated with perineal hernias is pain; there has only been 1 case in the literature involving bowel incarceration. ${ }^{6}$ This is the first reported case of large bowel incarceration associated with a perineal hernia. The risk factors most often associated with the development of acquired hernias are pregnancy, obesity, ascites, previous cancer operations, exposure to chemoradiotherapy, and smoking. ${ }^{5,7}$ Other than obesity, the patient had no other risk factors.

Acquired perineal hernias are usually associated with invasive, extensive surgeries involving the pelvic floor; there has only been 1 reported case of a perineal hernia associated with a patient undergoing sacrospinous fixation. ${ }^{8}$ Most of these hernias appear within 1 year following the surgery, ${ }^{1}$ which is what occurred in the present case (at $\sim 6$ months). The anterior types of perineal hernias, categorized based on their position relative to the transverse perineal muscle, occur exclusively in females. They emerge through the urogenital diaphragm and may present as a labial mass or a swelling between the anus and ischial tuberosity. ${ }^{1}$ This patient's hernia involved the right labia and the right paralabial region. The treatment for symptomatic perineal hernias is surgical. All surgical approaches involve dissection of the hernia sac, reduction of the contents, excision of the sac, and repair of the defect. ${ }^{5}$ The team in this case opted to use an abdominoperineal approach in order to provide enhanced visualization and to allow for manipulation of the hernia from both above and below.

There were several factors that could have influenced the creation and recurrence of the perineal hernia in this patient. One factor was the constant elevated intra-abdominal pressure

Table 1. A Summary of Recently Published Experiences Involving the Repair of Secondary Acquired Perineal Hernias and the Use of a Variety of Different Meshes

\begin{tabular}{|c|c|c|c|}
\hline Author(s) & $\begin{array}{c}\text { Initial surgery prior to the development } \\
\text { of the perineal hernia }\end{array}$ & Mesh used in hernia repair & $\begin{array}{l}\text { Recurrence of } \\
\text { perineal hernia after } \\
\text { mesh placement }\end{array}$ \\
\hline \multirow[t]{2}{*}{ Berendzen \& Copas ${ }^{5}$} & \multirow[t]{2}{*}{$\begin{array}{l}\text { Abdominoperineal resection of } \\
\text { adenocarcinoma of the rectum in a } \\
67 \mathrm{y} / \mathrm{o} \text { male }\end{array}$} & $\begin{array}{l}\text { Proceed }^{\mathrm{TM}} \text { synthetic polypropylene } \\
\text { nonabsorbable surgical mesh } \\
\text { (Ethicon, Somerville, NJ) }\end{array}$ & Yes \\
\hline & & $\begin{array}{l}\text { GynecareProlift }{ }^{\circledR} \text { synthetic nonab- } \\
\text { sorbable pelvic floor repair system } \\
\text { (Ethicon) }\end{array}$ & No \\
\hline Casasanta \& Moore $^{9}$ & $\begin{array}{l}\text { Laparoscopic abdominoperineal } \\
\text { resection of adenocarcinoma of the } \\
\text { rectum in a } 48 \mathrm{y} / \mathrm{o} \text { male }\end{array}$ & $\begin{array}{l}\text { Marlex synthetic high-density } \\
\text { polyethylene nonabsorbable mesh }\end{array}$ & No \\
\hline Ryan et al. ${ }^{7}$ & $\begin{array}{l}\text { Laparoscopic abdominoperineal resec- } \\
\text { tion of squamous-cell carcinoma of } \\
\text { the rectum in a } 69 \mathrm{y} / \mathrm{o} \text { male }\end{array}$ & $\begin{array}{l}\text { Synthetic-Composix nonabsorb- } \\
\text { able E/X Oval, Bard Nordic, } \\
\text { Sweden ellipse mesh }\end{array}$ & No \\
\hline \multirow[t]{2}{*}{ Kathju et al. ${ }^{10}$} & \multirow{2}{*}{$\begin{array}{l}\text { Abdominoperineal resection of } \\
\text { adenocarcinoma of the rectum in a } \\
56 \text { y/o male, followed by explorative } \\
\text { laparotomy }\end{array}$} & Vicryl synthetic absorbable mesh & Yes \\
\hline & & $\begin{array}{l}\text { DermaMatrix absorbable dermal } \\
\text { graft }\end{array}$ & No \\
\hline \multirow[t]{2}{*}{ Portilla et al. ${ }^{11}$} & \multirow[t]{2}{*}{$\begin{array}{l}\text { Abdominoperineal resection of } \\
\text { adenocarcinoma of the rectum in a } \\
69 \mathrm{y} / \mathrm{o} \text { male }\end{array}$} & $\begin{array}{l}\text { PerFix }{ }^{\circledR} \text { nonabsorbable plug mesh } \\
\text { covered by a } 6.4 \mathrm{~cm} \text { Ventralex }{ }^{\circledR} \\
\text { patch (Bard, Davol Inc. Cranston, } \\
\text { RI) }\end{array}$ & Yes \\
\hline & & $\begin{array}{l}\text { PerFix nonabsorbable plug mesh } \\
\text { (Bard, Davol Inc.) }\end{array}$ & No \\
\hline Rayhanabad et al. ${ }^{12}$ & $\begin{array}{l}\text { Laparoscopic abdominoperineal resec- } \\
\text { tion of squamous-cell carcinoma of } \\
\text { the anus in a } 67 \mathrm{y} / \mathrm{o} \text { male }\end{array}$ & $\begin{array}{l}\text { Bard Composix nonabsorbable } \\
\text { mesh (Davol) }\end{array}$ & No \\
\hline Silva-Filho et al. ${ }^{8}$ & $\begin{array}{l}\text { Sacrospinous colpoplexy with anterior } \\
\text { repair in a } 69 \mathrm{y} / \mathrm{o} \text { female }\end{array}$ & $\begin{array}{l}\text { Synthetic nonabsorbable polypro- } \\
\text { pylene mesh (Ethicon) }\end{array}$ & No \\
\hline
\end{tabular}

y/o, years old. 
that she experienced related to her occupation. Other factors included the possibility of impaired wound healing and weakened musculature as a result of prior surgeries. Another factor related to the recurrence of her hernia could have been the mesh chosen for repair. During her first hernia repair, the team opted to use a biologic, absorbable mesh. The fact that the mesh used was absorbable combined with her constant elevated intra-abdominal pressure and her history of pelvic surgeries could have promoted the recurrence of her perineal hernia. Table 1 demonstrates the experiences of other surgical teams in repairing secondary acquired perineal hernias, using a variety of different meshes. ${ }^{5,7-12}$

\section{Conclusions}

Secondary acquired perineal hernias are a rare complication of extensive pelvic surgery. Although most are asymptomatic, surgical intervention is warranted when symptoms are present. Currently, there is no consensus regarding the management of perineal hernias. Several factors may influence the development and possible recurrence of secondary acquired perineal hernias, including: lifestyle, occupation, gestational history, and past medical and surgical history. The experience described here may suggest the use of a nonabsorbable mesh to prevent recurrence, although current literature reports success rates that are fairly similar for users of both types of mesh (absorbable and nonabsorbable). As such, it cannot yet firmly be concluded that one type of mesh is superior to the other in preventing recurrence. Therefore, management of these cases is still very much open to debate.

\section{Disclosure Statement}

No competing financial conflicts exist.

\section{References}

1. Cali RL, Pitsch RM, Blatchford GJ, Thorson A, Christensen MA. Rare pelvic floor hernias. Dis Colon Rectum 1992;35:604.
2. Stamatiou D, Skandalakis JE, Skandalakis LJ, Mirilas P. Perineal hernia: Surgical anatomy, embryology, and technique of repair. Am Surg 2010;5:474.

3. Ruthledge RN, Smith JP, Wharton JT, et al. Pelvic exenteration: An analysis of 296 patients. Am J Obstet Gynecol 1977;129:881.

4. Bent A, Ostergard D, Cundiff G, Swift S. Ostergard's Urogynecology and Pelvic Floor Dysfunction, 5th ed. Philadelphia: Lippincott Williams \& Wilkins, 2002.

5. Berendzen J, Copas P. Recurrent hernia repair: A novel approach. Hernia 2011;May 17:e-pub ahead of print.

6. Khalil PN, Kleespies A, Angele MK, Bruns CJ, Siebeck M. Small bowel incarceration in recurrent perineal hernia. Int J Colorectal Dis 2011;26:957.

7. Ryan S, Kavanagh DO, Neary PC. Laparoscopic repair of postoperative perineal hernia. Case Report Med 2010; August 9; e-pub ahead of print.

8. Silva-Filho AL, Santos-Filho AS, Figueiredo-Netto O, Triginelli SA. Uncommon complications of sacrospinous fixation for treatment of vaginal vault prolapsed. Arch Gynecol Obstet 2005;271:358.

9. Casasanta M, Moore LJ. Laparoscopic repair of a perineal hernia. Hernia 2010;December 1:e-pub ahead of print.

10. Kathju S, Lasko LA, Medich DS. Perineal hernia repair with acellular dermal graft and suture anchor fixation. Hernia 2011;15:357.

11. Portilla AG, Martín E, de Lecea CM, et al. Recurrent postoperative perineal hernia: Laparoscopic redo mesh repair. Hernia 2010;14:535.

12. Rayhanabad J, Sassani P, Abbas MA. Laparoscopic repair of perineal hernia. JSLS 2009;13:237.

Address correspondence to:

Yasser Rodriguez, MD, MBA 7300 SW 93rd Avenue, Suite 200 Miami, FL 33173

E-mail: yrodriguez1@med.miami.edu 